\title{
Current concepts in clinical and laboratory assessments of autonomic nervous system activity
}

\author{
Łukasz Dobrek ${ }^{1}$, Piotr Thor ${ }^{1}$ \\ ${ }^{1}$ Department of Pathophysiology, Jagiellonian University Collegium Medicum, Krakow, Poland
}

Dobrek $\measuredangle$, Thor P. Current concepts in clinical and laboratory assessments of autonomic nervous system activity. J Pre-Clin Clin Res. 2015; 9(1): 63-68. 10.5604/18982395.1157579

\section{Abstract}

Introduction and objective. As the autonomic nervous system (ANS) dysfunction is present in course of many disorders, an objective assessment of the ANS function is very important. In practice, the assessment is difficult, and based rather on indirect analysis of autonomically-controlled cardiovascular reflexes, than on direct recording of activity of central or peripheral autonomic structures.

The aim of our paper was to discuss briefly current, clinical and scientific ANS investigations, as well as possible future methods of autonomic activity evaluation.

A brief description of the state of knowledge. The review presents a short outline of autonomic function assessments based on clinical autonomic tests (e.g. "Ewing's battery") and discusses the heart rate variability (HRV) study, as currently popular and widespread option of analysis of the ANS activity. Other, complementary methods, including the baroreceptor sensitivity testing, microneurography or plasma norepinephrine measurement were also mentioned. The article also provides premises related to the determination of selected neuropeptides in plasma or saliva as an innovative concept of autonomic activity assessment.

Summary. The available, clinical, non-invasive methods used for assessment of the ANS function are still relatively sparse and, in fact, a surrogate for direct ANS assessment. New methods of autonomic tension determination are still needed that would allow a more complete and reliable assessment. Reports of potential new laboratory markers of the ANS activity (NPY and VIP assay) bring some hope.

\section{Key words}

autonomic nervous system, autonomic tests, heart rate variability (HRV), noradrenaline, neuropeptides

\section{INTRODUCTION AND OBJECTIVE}

Organization of the autonomic nervous system. The autonomic nervous system (ANS) supplies all organs and, together with the endocrine and the immunological systems, it is responsible for the regulation and integration of body function. The ANS, with the above-mentioned systems, controls body homeostasis, which means a dynamic adjustment of physiological activity to the continuously changing external and internal environment, to adapt the body to the current needs $[1,2,3]$. Homeostasis is an involuntary phenomenon, occurring usually through a system of negative feedback, involving the central and peripheral autonomic structures.

Anatomically the ANS is divided into two parts: the sympathetic (adrenergic) and parasympathetic (cholinergic) systems. The sympathetic component originates from central neurons located in the front area of the ventro-lateral part of the medulla oblongata ( $R V L M$ - rostral ventrolateral medulla), gigantocellular nucleus, raphe nuclei, adrenergic area of the brain pons and the paraventricular hypothalamic nucleus. They are regarded to be specific pacemakers, tonically controlling sympathetic, pre-ganglionic neurons in the gray matter of the spinal cord (segments Th1-Th12 and L1-L3) in response to afferent signals reaching the

Address for correspondence: Łukasz Dobrek, Department of Pathophysiology, Jagiellonian University Collegium Medicum, Czysta 18, 31-121 Kraków, Poland E-mail: lukaszd@mp.pl

Received: 03 March 2015; accepted: 22 May 2015 brain. Postganglionic, sympathetic fibres, supplying target organs and releasing noradrenaline (NA) as the main neurotransmitter, originate from the paravertebral ganglia creating symmetric sympathetic trunks.

The parasympathetic (PS) ANS part involves the central structure (located above the RVLM), at the back of the ventromedial medulla area, neurons constituting the CVLM (caudal ventrolateral medulla) centre, as well as other structures: nucleus of the solitary tract, periaqueductal gray and spinal cord (segments S2-S4). The CVLM interacts with central sympathetic components, and - on one hand - inhibits their activity, and on the other, stimulates the preganglionic parasympathetic fibres originating from other centrallylocated PS structures. The parasympathetic, intramural ganglia give rise to postganglionic fibres in terminal organs. The most important parasympathetic innervation involves vagus nerve branches, supplying both chest and abdomen via the acetylcholine (Ach) release $[2,4]$

Primary and secondary autonomic disorders and symptoms of dysautonomia. The ANS dysfunction results from both primary disorders, directly affecting ANS, and from multiple and diverse diseases affecting other organs, where they trigger pathological autonomic disturbances [3]. Examples of clinical entities associated with autonomic dysfunction are given in the Table 1.

There are also many drugs that influence autonomic function, either by their impact on adrenergic or cholinergic receptors or by other, miscellaneous mechanisms. The most important ones are also shown in Table 1. 
Table 1. Classification of factors and diseases affecting autonomic nervous system and causing its dysfunction [1,5]

\begin{tabular}{|c|c|c|}
\hline & \multicolumn{2}{|l|}{ Examples } \\
\hline $\begin{array}{l}\text { Drugs or } \\
\text { toxins }\end{array}$ & \multicolumn{2}{|c|}{$\begin{array}{l}\text { centrally or peripherally acting a / } \beta \text { - sympathomimetics or } \\
\text { sympatholytics } \\
\text { parasympathomimetics or parasympatholytics } \\
\text { others: tricyclic antidepressants, phenothiazines, antihistaminics, } \\
\text { vincristine, cis-platin, taxol } \\
\text { Metals: thallium, arsenic, mercury, organophosphorus inhibitors }\end{array}$} \\
\hline \multirow[b]{2}{*}{$\begin{array}{l}\text { Diseases } \\
\text { affecting } \\
\text { the brain }\end{array}$} & Primary & $\begin{array}{l}\text { Multiple system atrophy (Shy-Drager syndrome) } \\
\text { Parkinson disease } \\
\text { Machado-Joseph disease }\end{array}$ \\
\hline & Secondary & $\begin{array}{l}\text { Stroke } \\
\text { Epilepsia } \\
\text { Shapiro syndrome } \\
\text { Neuroleptic malignant syndrome } \\
\text { Brain tumours }\end{array}$ \\
\hline \multirow{8}{*}{$\begin{array}{l}\text { Diseases } \\
\text { affecting } \\
\text { the spinal } \\
\text { cord } \\
\text { and/or } \\
\text { peripheral } \\
\text { autonomic } \\
\text { fibers }\end{array}$} & $\begin{array}{l}\text { Congenital / } \\
\text { Hereditary }\end{array}$ & $\begin{array}{l}\text { Nerve growth factor deficiency } \\
\text { Familial amyloid neuropathy } \\
\text { Riley-Day syndrome (familial dysautonomia) }\end{array}$ \\
\hline & Metabolic & $\begin{array}{l}\text { Diabetes mellitus } \\
\text { Chronic renal failure } \\
\text { Chronic liver failure } \\
\text { Alcohol induced }\end{array}$ \\
\hline & Inflammatory & Guillain-Barre syndrome \\
\hline & $\begin{array}{l}\text { Auto- } \\
\text { immunologic }\end{array}$ & $\begin{array}{l}\text { Multiple sclerosis } \\
\text { Amyotrophic lateral sclerosis (Lou-Gehrig disease) }\end{array}$ \\
\hline & Infections & $\begin{array}{l}\text { Tetanus } \\
\text { HIV } \\
\text { Chagas' disease } \\
\text { Lyme disease } \\
\text { Diphteria }\end{array}$ \\
\hline & Neoplasia & Lambert-Eaton paraneoplastic syndrome \\
\hline & Surgery & $\begin{array}{l}\text { Vagotomy } \\
\text { Dumping syndrome }\end{array}$ \\
\hline & Trauma & Spinal cord transection \\
\hline
\end{tabular}

An autonomic insufficiency may result in dysfunction of selected organs, but most symptoms of dysautonomia are non-characteristic and have a pleiotropic character, involving clinical manifestations from various systems. An autonomic dysfunction may manifest either in the ANS failure or in its over-activity. The most significant signs and symptoms of autonomic dysfunction are summarized in Table 2.

Taking into consideration the diversity of clinical symptoms of dysautonomia (being a result of many different diseases mentioned above, as well as a possible, etiologic factor of other secondary disorders), it is important to be able to assess the ANS functional status in an reliable and objective way.

\section{DESCRIPTION OF THE STATE OF KNOWLEDGE}

ANS function assessment is difficult, considering the fact that, in practice, there is no direct method of inspection of the autonomic innervation. For this reason, an indirect assessment has to be performed, based on observation of autonomically-mediated reflexes in a patient. The fact that the ANS function is continuously modulated by a number of external as well as internal factors, of both physiological (stress, exercise, food, stimulants) and pathological nature (co-existing disturbances, drugs) is an additional difficulty. For these reasons, the assessment of the functional ANS state is difficult and time consuming, requires development
Table 2. Selected clinical manifestations of autonomic dysfunction and an overview of autonomic testing methods $[1,5,9]$

\begin{tabular}{|c|c|c|}
\hline & Symptoms & Possible testing \\
\hline $\begin{array}{l}\text { Cardio- } \\
\text { vascular }\end{array}$ & $\begin{array}{l}\text { postural hypotension } \\
\text { supine hypertension } \\
\text { paroxysmal hypertension } \\
\text { fainting associated with voiding, } \\
\text { defecation, or after long-standing } \\
\text { resting tachycardia / bradycardia } \\
\text { episodes }\end{array}$ & $\begin{array}{l}\text { Valsava manoevour } \\
\text { Deep breathing test } \\
\text { Tilt / Orthostatic test } \\
\text { Hand grip test } \\
\text { Ice water test } \\
\text { Face immersion test } \\
\text { Eyeballs oppression } \\
\text { Carotid sinus massage }\end{array}$ \\
\hline $\begin{array}{l}\text { Gastro- } \\
\text { intestinal }\end{array}$ & $\begin{array}{l}\text { nausea, vomiting } \\
\text { diarrhoea / constipation } \\
\text { dysphagia } \\
\text { early postprandial distress syndrome } \\
\text { gastroparesis }\end{array}$ & $\begin{array}{l}\text { Gastro-intestinal passage } \\
\text { Barium contrast image } \\
\text { Endoscopy } \\
\text { Electrogastrography }\end{array}$ \\
\hline $\begin{array}{l}\text { Urinary and } \\
\text { sexual }\end{array}$ & $\begin{array}{l}\text { urine urgency } \\
\text { urine retention } \\
\text { urine incontinence } \\
\text { erectile / ejaculation failure } \\
\text { retrograde ejaculation } \\
\text { priapism }\end{array}$ & $\begin{array}{l}\text { Urodynamic studies } \\
\text { Urography } \\
\text { 24-hour urine collection } \\
\text { Penile plethysmography }\end{array}$ \\
\hline Respiratory & $\begin{array}{l}\text { sleep apnea } \\
\text { snoring }\end{array}$ & Polysomnography \\
\hline Eye & $\begin{array}{l}\text { abnormal pupillary reaction to light } \\
\text { ptosis }\end{array}$ & $\begin{array}{l}\text { Pharmacological evaluation } \\
\text { of pupils } \\
\text { Schirmer tear secretion test }\end{array}$ \\
\hline Sudomotor & $\begin{array}{l}\text { hipohidrosis / hyperhidrosis } \\
\text { dyslacrimation }\end{array}$ & Sympathetic skin response \\
\hline $\begin{array}{l}\text { Thermo- } \\
\text { regulation }\end{array}$ & $\begin{array}{l}\text { resting hypothermia / hyperthermia } \\
\text { labile body temperature }\end{array}$ & $\begin{array}{l}\text { Thermoregulatory sweating } \\
\text { test }\end{array}$ \\
\hline
\end{tabular}

and standardization of procedures, and is a very important element in the patient's pathophysiological description.

In the complex evaluation of the ANS activity, some widely-known, routine clinical methods are used, although less commonly performed scientific methods may also be applied. Some laboratory attempts at autonomic activity assessments are additionally mentioned in research studies. However, at present, they are believed to be only experimental methods of no well-established importance and they require further analysis regarding their suitability.

Medical interview and physical examination in dysautonomia. Clinical evaluation of a patient's autonomic nervous system is based on detailed anamnesis and physical examination, focusing on the detection of potential symptoms of dysautonomia listed above (Tab. 2). In the medical interview, questions concerning cardiac, vasomotor and gastrointestinal disturbances, bladder dysfunction or sexual dysfunction are of special interest [5]. The differential diagnosis targeted on diseases is important (Tab. 1). The quantitative dysautonomia symptom assessment is possible using some specific questionnaires, e.g. the Autonomic Symptom Profile [6] or the Composite Autonomic Scoring Scale [7], as well as Lowe modified questionnaire for diabetic autonomic disturbances used by Polish practitioners [8]. The physical examination includes pupil examination, skin sweating response, gooseflesh reaction, body temperature, and vasomotor reactions (dermographism) [5].

Physical examination is supplemented by the so-called 'autonomic tests'. As mentioned above, knowledge of the selected, autonomically-mediated physiological reflexes and their comparison with the reactions observed in a patient allows drawing conclusions about the ANS functional state. 
Taking into account the complex clinical features of dysautonomia, many tests have been developed for the detection of specific disturbances (Tab. 2). However, most of them are complicated and too expensive, requiring hightech equipment and staff. They are considered useful only in advanced autonomic research, but useless in clinical practice.

Clinical and experimental autonomic tests. In common practice, simple cardiovascular reflexes are evaluated, measured by heart rate (in ECG) or blood pressure changes, triggered by specific provocative manoeuvers. However, there is no single test that could precisely evaluate the function of the sympathetic or parasympathetic ANS part $[3,5]$. Thus, several tests are performed, some of which are traditionally perceived as targeted on the sympathetic system activity assessment, and others as tests evaluating predominantly the parasympathetic function.

The standardized test dedicated to the parasympathetic evaluation comprises Valsalva manoeuver, deep breathing and tilt (orthostatic) tests with the heart rate changes assessment ('30/15 ratio') in the ECG recordings. Furthermore, eyeballs oppression, carotid sinus massage or the facial immersion test (all causing bradycardia) are recommended as a second choice test $[2,5,9]$.

Standard tests used for evaluation of mostly the sympathetic activity include: qualitative sweating tests (skin test with ninhydrin, iodine-starch Minor test), an orthostatic test with postural systolic blood pressure changes evaluation, a prolonged, isometric hand-grip test with changes in diastolic blood pressure assessment, as well as the hand immersion in ice water test with changes of blood pressure and heart rate evaluation, an assessment of postprandial blood pressure changes and an oculomotor test $[2,5,10]$.

However, in common clinical practice, four of abovementioned tests (Valsalva maneuver, deep breathing test, tilt - orthostatic test and hand grip test) are routinely performed. They constitute the - so-called - 'Ewing's tests battery' [2, 3, 5], described for the first time and introduced into clinical practice in the 1970's and 1980's, and despite the passage of time, they are still used as a standard autonomic test set $[11,12,13]$. Repeatable performance of these tests as the ANS function monitoring, has been introduced into the guidelines and recommendations for practitioners in the management of patients with diabetes or post-myocardial infarction. Detailed information regarding the methodology and interpretation of the above-mentioned autonomic tests can be found in many papers, including those mentioned in the authors' review $[2,3,5]$.

Heart rate variability as a current common method for ANS evaluation. Another popular method for ANS assessment is the heart rate variability (HRV). Contrary to its direct meaning, HRV is not the investigation of changes in the heart rate, but a detailed analysis of differences of R-R intervals (also known as 'normal-normal' - N-N intervals) in the cardiac sinus rhythm, remaining under a constant autonomic control. The examination is based on the observation that $\mathrm{R}-\mathrm{R}$ intervals recorded in resting ECG are not constant, but continuously fluctuate around the mean value, and the R-R variability depends on the mutual interactions between the sympathetic and parasympathetic part and their impact on the sinus node activity $[3,14,15]$. The HRV analysis is based on short (usually 5-20 minutes) or long-lasting (24-hour
Holter) ECG recordings with subsequent time or spectral (frequency) domain analysis. In time domain analysis, which is based on the main, primary parameter, the mean R-R interval value, some parameters of a statistical nature are also obtained, e.g. standard deviation of all R-R intervals (SDR-R), mean value of successive absolute differences (MSD), the square root of the mean of the sum of the squares of differences between adjacent R-R intervals (rMSSD), and the percentage of successive R-R intervals differing more than $50 \mathrm{~ms}$ (pNN50). It is generally agreed that the SDR-R value reflects the global activity of the entire ANS, while rMSSD and pNN50 parameters are considered to be indicators of the parasympathetic tension $[14,15,16,17,18,19]$.

The spectral (frequency) domain analysis is based on the distribution of R-R intervals in relation to cyclic, autonomically-modulated activity of the sinoatrial node associated with three principal rhythms: at very low (VLF), low (LF) and high frequency (HF) ranges. The system of interconnections in many systems (including cardiovascular and respiratory) is the source of these oscillations. Instability in one interaction generates an instability in the entire system. The spectral HRV analysis allows for obtaining the so-called HRV spectrum, and determination of individual spectral components. The distinction of individual HRV spectral components allows characterization of the cyclical nature of the heart rate changes, hidden in a seemingly chaotic R-R intervals variability, based on the analysis of $\mathrm{R}-\mathrm{R}$ changes function as a complex wave, distributing into simple waves of a certain frequency using the auto-regression method or fast Fourier transformation $[2,14,15,16,17,18,19]$. In short HRV recordings, three essential components may be distinguished: HF, LF and VLF, at high (about $0.15-0.4 \mathrm{~Hz}$ ), low (about $0.04-0.15 \mathrm{~Hz}$ ) and very low (about $0.003-0.04 \mathrm{~Hz}$ ) frequencies, respectively. Moreover, the ultra low frequency (ULF; < $0.003 \mathrm{~Hz}$ ) component may be also distinguished in long-lasting HRV recordings [2, 3, 14, 15, 16, 17, 18, 19].

Changes in the HRV power spectrum and its individual components at rest and during assessed reflexes are of physiological significance. The HRV total power spectrum is the determinant of the overall autonomic activity. The HF component is generally defined as a marker of isolated parasympathetic tension. This component is mostly respirationmediated and determined by the frequency of respiratory sinus arrhythmia, thus it is referred to be a 'respiratory band'. The LF component reflects the activity of both ANS branches, with the sympathetic part as a primary contributor. ULF and VLF generally are regarded to indicate the overall activity of slow thermoregulatory mechanisms, chemoreceptors stimulations or various neuroendocrine mechanisms (e.g. the renin-angiotensin-aldosterone system). Similar to LF, the VLF measure was found to be more determined by a sympathetic activity. Moreover, the HRV spectrum subjected to a process of normalization results in two additional parameters: nLF and nHF. According to the generally accepted HRV guidelines, they are clear markers of sympathetic or parasympathetic tension, respectively $[14,15,16,17,18,19]$.

Other methods used in ANS assessment. Baroreflex sensitivity (BRS) testing, based on the mutual dependence between blood pressure and heart rate changes, is the complementary method of the ANS function assessment. BRS is defined as the change in interbeat interval (in [milliseconds]) per unit change in blood pressure (in [mmHg]) [20]. In this method, baroreceptors are 
pharmacologically stimulated by administration of an agent raising the blood pressure that leads to reflex bradycardia due to the parasympathetic stimulation. The baroreceptor response can be also tested using its decompression, achieved after administration of a strong, hypotensive agent (e.g. sodium nitroprusside or nitroglycerine). The baroreflex sensitivity consists in determination of the slope of the linear regression between beat-to-beat systolic blood pressure values and R-R intervals values $[3,20,21]$. There is also a more advanced 'sequence method' in which continuous blood pressure and $\mathrm{R}-\mathrm{R}$ recordings are scanned for sequences in which systolic blood pressure and R-R intervals concurrently increase or decrease for at least three following beats, and the relationship defining those changes also indicates the baroreflex sensitivity $[3,20,21]$.

So far, this paper has mentioned clinical, indirect methods of ANS assessment, mostly based on cardiovascular reflexes. Currently, there are also tests providing a direct measurement of peripheral autonomic afferent and efferent traffic to muscle and skin using the microneurography technique $[22,23]$. Recording of efferent discharge in skin and muscle $\mathrm{C}$-fibres is referred to as 'muscle sympathetic nerve activity' (MSNA), in which the electrode tip penetrates the muscle nerve fascicles, or 'skin sympathetic verve activity (SSNA), in which recordings are taken from skin nerve fascicles.

Sympathetic microneurography seems to be useful in demonstrating autonomic dysfunctions concerning the thermoregulation or blood pressure control [24]. Recordings of afferent discharge from cutaneous and muscle spindle are also performed to the analyze the neural mechanisms of motor control. Analysis of afferent discharges from cutaneous mechanoreceptors reveals mechanoreception dysfunctions, such as vibrotactile sensation or paresthesia. Recordings of afferent discharges from nociceptors in muscle and skin indicate valuable objective signals related to pain and other sensations, such as itch [24].

Current and future, possible laboratory assays estimating autonomic activity - Plasma noradrenaline measurement. Assessment of the ANS function using the methods described above is difficult and time-consuming. Thus, there are ongoing studies aimed at finding some reliable laboratory parameters indicating autonomic activity. Plasma acetylcholine measurement as a marker of parasympathetic tension is impractical because the substance is highly labile and quickly decomposed by acetylcholinesterase, and thus cannot be quantified [3]. In contrast, the sympathetic activity is usually assessed by the plasma noradrenaline concentration assay, according to the assumption adopted in the 1980's that it reflects the 'overall' sympathetic activity $[25,26]$. Although the measurement provides some useful information, it has also some significant limitations, mostly associated with the fact that circulating NA represents only a fraction of the amount of the neurotransmitter package secreted from nerve terminals. Moreover, the plasma noradrenaline level is influenced by its clearance, metabolism and uptake from the circulating blood. Finally, the plasma NA measurement does not allow discrimination between the central (increased secretion) and peripheral (reduced clearance) mechanism of increase of that neurotransmitter, nor for differentiation of decreased NA level, due to diminished central noradrenergic structures activity or increased peripheral clearance [27]. Hence, the noradrenaline spillover rate measurement has been proposed as a better surrogate for sympathetic tension determination, instead of measurement of total, static serum noradrenaline concentration.

The metabolic clearance rate method, based on noradrenaline isotope plasma dilution, allows calculation of the confounding influence of plasma NA clearance, in which a small, radiolabelled amount of NA is administrated intravenously. The substance is subject to tissue uptake, which is subtracted from the plasma NA level. The total, remaining radio-labeled and intact NA level assay allows determination of the additional neurotransmitter amount released from neuroeffector junctions [3]. Noradrenaline spillover measurement tests the rate at which the released norepinephrine enters plasma, rather than the rate of release of norepinephrine from sympathetic terminals. Since the overflow of released norepinephrine to plasma is influenced by the parallel neuronal reuptake, the performance of tests of norepinephrine reuptake, together with the metabolic clearance rate measurements, provides comprehensive information, e.g. answering the question whether the higher NA spillover is due to increased norepinephrine release, or its deficient reuptake [28].

Moreover, radiotracer-derived measurements of the appearance rate of noradrenaline in plasma from individual organs may also be a technique complementary to microneurography. That method cannot access sympathetic nerves of internal organs. The relationship between the sympathetic nerve firing in a selected organ (e.g. heart or kidneys) and the noradrenaline overflow rate, estimated in regional blood samples, justifies using regional noradrenaline spillover as a surrogate for nerve traffic measurements [29].

Assay of plasma neuropeptides co-released with noradrenaline or acetylcholine. Noradrenergic, sympathetic fibres, as well as cholinergic, parasympathetic fibres, also demonstrate the ability to release some non-cholinergic non-adrenergic (NANC) neurotransmitters, apart from noradrenaline or acetylcholine, respectively. Neuropeptide $\mathrm{Y}$ (NPY) is one of them, a substance that has been found in sympathetic neurons, co-stored and co-released with catecholamine [30, 31]. NPY is a polypeptide consisting of 36 amino acid units, presenting a high homology with the pancreatic polypeptide. NPY immunoreactivity neurons have been found in both the central and peripheral nervous systems. The highest brain NPY content was found in supraoptic and paraventricular hypothalamic and thalamic nuclei, and in medulla oblongata neurons that belong to the central sympathetic structures, as mentioned in the Introduction $[32,33]$. The NPY impact on sympathetic neurons is ambiguous. There are reports of the inhibitory NPY role in central sympathetic activity, and that the compound is regarded to diminish stress-related sympathetic consequences [34], thus exerting an anxiolytic effect.

In contrast, there is a general agreement, that NPY has an excitatory effect in relation to the peripheral sympathetic nervous system, enhancing its activity synergistically with catecholamines and glucocorticoids [35]. NPY-containing neurons are located in sympathetic ganglia and in tissues receiving abundant sympathetic innervation (blood vessels, heart, spleen, kidneys, digestive, respiratory and urogenital tracts). Thus, peripherally, NPY is co-responsible for vasoconstriction (producing a strong effect resistant to alpha blockade), vascular smooth muscle cells proliferation, stimulated hyperlipidaemia and hyperglycaemia. Moreover, 
NPY participates in neointimal formation, macrophage infiltration of the vascular injury, and subsequent atherosclerotic plaque. NPY is also reported to cause increase of the renal artery resistance and decrease in renal blood flow. Together with the RAA system activated because of the high sympathetic tension, NPY contributes to the development of hypertension. High plasma NA level has been found in patients with some clinical conditions associated with sympathetic overactivity, such as congestive heart failure or myocardial ischaemia [35, 36]. Considering the physiological premises listed above, the concept of determining plasma NPY concentration as a laboratory marker of sympathetic activity seems to be justified.

Parasympathetic efferent fibres, in turn, demonstrate cosecretion of another neuropeptide - the vasoactive intestinal peptide (VIP). VIP is a 28 -amino acid polypeptide that was first demonstrated to be a potent vasodilatatory agent in the duodenum. However, further studies revealed that VIP is distributed in the peripheral innervation of various tissues and exhibits multiple effects. Apart from vasodilatation (mostly observed in intestinal, hepatic, coronary and pulmonary vessels), it relaxes the lower oesophageal sphincter and sphincter of Oddi, as well as bronchial smooth muscle, facilitates intestinal and pancreatic secretion, but inhibits gastric secretion, and promotes the secretion of both insulin and glucagon in a glucose-dependent manner. VIP also plays an immunomodulatory role, and inhibits the macrophage release of proinflammatory nitric oxide or tumour necrosis factor and promotes the production of anti-inflammatory cytokines, such as interleukin-10 [37].

VIP-immunoreactive neurons are also broadly distributed in the central nervous system. They were found in the limbic area and in the periventricular grey matter of the diencephalon. They are also located in nucleus mamillaris lateralis, but sparse in the preoptic area, supraoptic nucleus and the paraventricularis nucleus $[32,38]$. Numerous reports of VIP and Ach co-transmission were published in 1980's and 1990 's $[39,40]$, and that concept is commonly accepted today [32]. Thus, similar to NPY for the sympathetic branch, VIP is proposed to be the marker of parasympathetic activity.

\section{SUMMARY}

Neuropeptides playing the role of co-transmitters in peripheral tissues seem to be the next, potential laboratory markers of the ANS activity, and there is an increasing number of papers focusing on the NPY and VIP measurements used to evaluate the autonomic activity. One of these is the study by El-Sayed et al. [41] which aimed to assess the cardiac autonomic function in patients with systemic lupus erythematosus and juvenile idiopathic arthritis (JIA) using serum levels of NPY and VIP as indicators of sympathetic and parasympathetic functions, respectively. Use of that method confirmed the autonomic neuropathy in both lupus and JIA patients (even in the absence of relevant symptoms), and concluded that serum autonomic neuropeptides (NPY and VIP) may be valuable markers of autonomic function and should be monitored in these patients [41].

Neuropeptides as novel salivary markers of ANS activity. Studies using saliva levels of the same neuropeptides involved in autonomic saliva secretion control are also worth mentioning. That concept is based on anatomical and physiological aspects of saliva secretion. VIP and NPY are important NANC mediators controlling saliva production, that may be found in the fluid. Some immunohistochemistry studies demonstrated high density of VIP-containing neurons around the ducts and blood vessels of the minor salivary glands in humans [42, 43]. However, in humans, the saliva is mostly secreted by submandibular and parotid glands. In contrast to the minor salivary glands, they receive both sympathetic and parasympathetic innervation $[44,45]$. Moreover, it was shown that saliva fluid secretion is mediated by a primarily cholinergic mechanism, while the production of saliva proteins (alpha-amylase) is under the control of both cholinergic and adrenergic mechanisms [46]. On the other hand, some animal studies revealed that both mucins and water production in sublingual salivary glands is controlled primarily by parasympathetic fibres (Ach, VIP) [40].

Taking into account the premises described above, few studies have been published so far using the saliva determination of both VIP and NPY as markers of the ANS activity $[47,48,49]$. However, that novel method is not widely used at present and it still requires further development. There are some objections, particularly concerning anatomical differences between the determinants of the salivary glands innervation in humans and animals, causing partial incompatibility in research on animals and humans. There are also differences in the participation of individual salivary glands in the saliva production in animals and humans [50]. Furthermore, due to the complex autonomic control of individual salivary glands, there is a tendency for VIP or NPY determination from a single, selected salivary gland, and not in the total saliva. However, it appears that the unique method using saliva as a medium for the determination of VIP / NPY as markers of the ANS activity is very interesting, and for this reason, studies on that subject should be continued.

\section{CONCLUSIONS}

Due to the existence of various clinical entities associated with primary or secondary autonomic dysfunctions manifested by complex, multisystem symptoms, the assessment of autonomic nervous system activity seems to be extremely important. However, from the practical point of view, such an assessment is difficult and predominantly indirect, based on the analysis of cardiovascular reflexes controlled by sympathetic and parasympathetic fibres. The classical, clinical functional ANS assessment involves both anamnesis and physical examination aimed at the diagnosis of dysautonomia, together with a set of the so-called, Ewing's autonomic tests: Valsalva manoeuver, orthostatic tilt test, deep breathing test, isometric hand grip test. Short and long (24-hour) ECG recordings, with a subsequent time- and spectral (frequency) heart rate variability analysis, are also performed. Other, complementary methods used in scientific research rather than in routine clinical ANS function assessment, include: baroreflex sensitivity testing or direct registration of the electrical activity of the autonomic fibres - microneurography.

Currently, a laboratory-based ANS activity assessment is practically impossible, except for the ambiguous plasma NA measurement, correlated with the sympathetic activity. However, many studies concerning the NANC neurotransmitters (especially some neuropeptides, e.g. NPY 
or VIP), co-released with the NA or Ach in the autonomic fibres, are carried out. These co-transmitters, also assayed in the plasma, are regarded to be good, potential indicators of the ANS activity. Moreover, according to some research, NPY and VIP levels reflecting the autonomic tension may be also measured in saliva. Some preliminary studies on the applicability of NPY and VIP as laboratory markers of the ANS activity are promising, and their further development and increasing significance can be expected.

\section{REFERENCES}

1. Mathias CJ. Autonomic diseases: clinical features and laboratory evaluation. J Neurol Neurosurg Psychiatry. 2003; 74(Suppl. III): 31-41.

2. Rydlewska A, Ponikowska B, Borodulin-Nadzieja L, Banasiak W, Jankowska EA, Ponikowski P. Ocena aktywności autonomicznego układu nerwowego związanej z odruchowa regulacja układu sercowonaczyniowego i oddychania. Kardiol Pol. 2010; 68(8): 951-957 (in Polish).

3.Zygmunt A, Stańczyk J. Methods of evaluation of autonomic nervous system function. Arch Med Sci. 2010; 6(1): 11-18.

4. Januszewicz W, Szczepańska-Sadowska E, Januszewicz A, Prejbisz A. Neurogenne aspekty nadciśnienia tętniczego. Nadciśn Tętn. 2008; 12(1): 1-11 (in Polish).

5. Mariańska K, Koszewicz M. Kliniczna ocean układu autonomicznego. Pol Przegl Neurol. 2008; 4(2): 51-57 (in Polish).

6. Suarez GA, Opfer-Gehrking KP, Offord MS, Atkinson EJ, O’Brien PC, Low PA. The autonomic Symptom Profile. A new instrument to assess autonomic symptoms. Neurology 1999; 52(3): 523-528.

7. Low PA. Clinical autonomic disorders: evaluation and management. $2^{\text {nd }}$ ed. Lippincott-Raven Publishers, Philadelphia; 1997: 3-175.

8. Zakrzewska-Pniewska B. Autonomiczny układ nerwowy w cukrzycy. Aktualn Neurol. 2004; 4(2): 116-121 (in Polish).

9. Budrewicz S. Standardowe badania kliniczne czynności autonomicznych - układ przywspółczulny. In: Podemski R. (ed.). Diagnostyka autonomicznego układu nerwowego I zaburzeń snu. Ed. 1. Wrocław, Wydawnictwo Medyczne Urban \& Partner; 2006: 5-22 (in Polish).

10. Budrewicz S. Standardowe badania kliniczne czynności autonomicznych - układ współczulny. In: Podemski R. (ed.). Diagnostyka autonomicznego układu nerwowego I zaburzeń snu. Ed. 1. Wrocław, Wydawnictwo Medyczne Urban \& Partner; 2006; 23-33 (in Polish).

11. Ewing DJ. Cardiovascular reflexes and autonomic neuropathy. Clin Sci Mol Med. 1978; 55(4): 321-327.

12. Ewing DJ, Clarke BF. Diagnosis and management of diabetic autonomic neuropathy. Br Med J. 1982; 285(6346): 916-918

13. Ewing DJ, Martyn CN, Young RJ, Clarke BF. The value of cardiovascular autonomic function tests: 10 years experience in diabetes. Diabetes Care 1985; 8(5): 491-498.

14. Malik M (ed.). Heart rate variability. Standards of measurement, physiological interpretation, and clinical use. Task Force of The European Society of Cardiology and The North American Society of Pacing and Electrophysiology. Eur Heart J. 1996; 17(3): 354-381.

15. Berntson GG, Bigger JT JR, Eckberg DL, Grossman P, Kaufmann PG, Malik M, et al. Heart rate variability: origins, methods, and interpretive caveats. Psychophysiology 1997; 34(6): 623-648.

16. Sztajzel J. Heart rate variability: a noninvasive electrocardiographic method to measure the autonomic nervous system. Swiss Med Wkly. 2004; 134 (35-36): 514-522.

17. Acharya UR, Joseph KP, Kannathal N, Lim CM, Suri JS. Heart rate variability: a review. Med Bio Eng Comput. 2006; 44(12): 1031-1051.

18. Karim N, Hasan JA, Ali SS. Heart rate variability - a review. J Basic Appl Sci. 2011; 7(1): 71-77.

19. ChuDuc H, NguyenPhan K, NguyenViet DA. Review of Heart Rate Variability and its Applications. APCBEE Procedia 2013; 7: 80- 85.

20. Swenne CA. Baroreflex sensitivity: mechanisms and measurement Neth Heart J. 2013; 21(2): 58-60.

21. La Rovere MT, Pinna GD, Raczak G. Baroreflex sensitivity: measurement and clinical implications. Ann Noninvasive Electrocardiol. 2008; 13(2): 191-207.

22. Gandevia SC, Hales JP. The methodology and scope of human microneurography. J Neurosci Methods. 1997; 74(2): 123-136.

23. Vallbo AB, Hagbarth KE, Wallin BG. Microneurography: how the technique developed and its role in the investigation of the sympathetic nervous system. J Appl Physiol. 2004; 96(4): 1262-1269.

24. Mano T, Iwase S, Toma S. Microneurography as a tool in clinical neuropsysiology to investigate peripheral neural traffic in humans. Clin Neurophysiol. 2006; 117(11): 2357-2384.
25. Wallin BG, Sundlof G, Eriksson BM, Dominiak P, Grobecker H, Lindblad LE. Plasma noradrenaline correlates to sympathetic muscle nerve activity in normotensive man. Acta Physiol Scand. 1981; 111(1): 69-73.

26. Goldstein DS, McCarty R, Polinsky RJ, Kopin IJ. Relationship between plasma norepinephrine and sympathetic neural activity. Hypertension 1983; 5(4): 552-559.

27. Sinski M, Lewandowski J, Abramczyk P, Narkiewicz K, Gaciong Z. Why study sympathetic nervous system? J Physiol Pharmacol. 2006; 57(Suppl. II): 79-92.

28. Esler M, Jennings G, Korner P, Willett I, Dudley F, Hasking G, et al. Assessment of human sympathetic nervous system activity from measurements of norepinephrine turnover. Hypertension 1988; 11(1): 3-20.

29. Esler M, Lambert G, Brunner-La Rocca HP, Vaddadi G, Kaye D. Sympathetic nerve activity and neurotransmitter release in humans: translation from pathophysiology into clinical practice. Acta Physiol Scand. 2003; 177(3): 275-284.

30. Lundberg JM, Terenius L, Hokfelt T, Martling CR, Tatemoto K, Mutt V, et al. Neuropeptide Y (NPY) - like immunoreactivity in peripheral noradrenergic neurons and effects of NPY on sympathetic function. Acta Physiol Scand. 1982; 116(4): 477-480.

31.Lundberg JM, Franco-Cereceda A, Hemsen A, Lacroix JS, Pernow J. Pharmacology of noradrenaline and neuropeptide tyrosine (NPY)mediated sympathetic cotransmission. Fundam Clin Pharmacol. 1990; 4(4): 373-391.

32. Burnstock G. Cotransmission in the autonomic nervous system. In: Buijs RM and Swaab DF, Eds. Handbook of Clinical Neurology. Autonomic Nervous System. Vol 117 ( $3^{\text {rd }}$ series), Elsevier; 2013: 23-35.

33. Decressac M, Barker RA. Neuropeptide $Y$ and its role in CNS disease and repair. Exp Neurol. 2012; 238(2): 265-272.

34. Heilig M. The NPY system in stress, anxiety and depression. Neuropeptides 2004; 38(4): 213-224.

35. Kuo LE, Zukowska Z. Stress, NPY and vascular remodeling: implications for stress-related diseases. Peptides 2007; 28(2): 435-440.

36. Pedrazzini T, Pralong F, Grouzmann E. Neuropeptide Y: the universal soldier. Cell Mol Life Sci. 2003; 60(2): 350-377.

37. Igarashi H, Fujimori N, Ito T, Nakamura T, Oono T, Nakamura K, et al. Vasoactive intestinal peptide (VIP) and VIP receptors - elucidation of structure and function for therapeutic applications. Int J Clin Med. 2011; 2(4): 500-508.

38. Petkó M, Ihionvien M. Distribution of substance P, vasoactive intestinal polypeptide and serotonin immunoreactive structures in the central nervous system of the lizard, Lacerta agilis. J Hirnforsch. 1989; 30(4): 415-423.

39. Costa M, Furness JB, Gibbins IL, Morris JL, Bornstein JC, LlewellynSmith IJ, et al. Colocalization of VIP with other neuropeptides and neurotransmitters in the autonomic nervous system. Ann N Y Acad Sci. 1988; 527: 103-109.

40. Culp DJ, Richardson LA. Regulation of mucous acinar exocrine secretion with age. J Dent Res. 1996; 75(1): 575-580.

41. El-Sayed ZA, Mostafa GA, Aly GS, El-Shahed GS, Abd El-Aziz MM, ElEmam SM. Cardiovascular autonomic function assessed by autonomic function tests and serum autonomic neuropeptides in Egyptian children and adolescents with rheumatic diseases. Rheumatology 2009; 48(7): 843-848.

42. Konttinen YT, Hukkanen M, Kemppinen P, Segerberg M, Sorsa T, Malmstrom M, et al. Peptide-containing nerves in labial salivary glands in Sjorgen's syndrome. Arthritis Rheum. 1992; 35(7): 815-820.

43. Feher E, Zelles T, Nagy G. Immunocytochemical localization of neuropeptide-containing nerve fibres in human labial glands. Arch Oral Biol. 1999; 44(Suppl. 1): S33-S37.

44. Ekstrom J, Asztely A, Tobin G. Non-adrenergic, non-cholinergic influences on parotid acinar degranulation in response to stimulation of the parasympathetic innervation in the anaesthetized rat. Exp Physiol. 1996; 81(6): 935-942.

45. Proctor GB, Carpenter GH. Regulation of salivary gland function by autonomic nerves. Auton Neurosci. 2007; 133(1): 3-18.

46. Jensen JL, Brodin P, Berg T, Aars H. Parotid secretion of fluid, amylase and kallikrein during reflex stimulation under normal conditions and after acute administration of autonomic blocking agents in man. Acta Physiol Scand. 1991; 143(3): 321-329.

47. Dawidson I, Blom M, Lundeberg T, Theodorsson E, Angmar-Mansson B. Neuropeptides in the saliva of healthy subjects. Life Sci. 1997; 60(4-5): 269-278.

48. Naito T, Itoh H, Takeyama M. Effects of hange-koboku-to on neuropeptide levels in human plasma and saliva. Biol Pharm Bull. 2003; 26(11): 1609-1613.

49. Satoh Y, Itoh H, Takeyama M. Effects of bakumondoto on neuropeptide levels in human saliva and plasma. J Trad Med. 2009; 26(3): 122-130.

50. Humphrey SP, Williamson RT. A review of saliva: normal composition, flow and function. J Prosthet Dent. 2001; 85(2): 162-169. 